\title{
Un fragment de dístics morals catalans Pep Vila
}

A la secció de manuscrits, entre els fulls solts i fragments de l'Arxiu Municipal de Girona, es conserva el full d'un còdex sense identificar que ara editem. Fa uns anys, en ocasió de l'inventari de pergamins d'aquest arxiu fet per l'amic Joan Villar, en vam obtenir una reproducció. Durant la preparació d'aquesta nota ens hem tornat a interessar per veure'n l'original, però ha resultat que ara per ara està traspaperat i no l'hem pogut consultar. Es tracta d'un únic foli de paper, aparentment sense foliació, però malauradament no hem pogut prendre'n les mides, comprovar la qualitat del paper, esbrinar si tenia alguna filigrana, o corroborar cap altre detall més enllà dels que s'observen a la fotografia.

L'escriptura és gòtica cursiva, del pas del segle XIV al XV. Totes les inicials, escrites amb tinta de color vermell, estan separades de la resta del vers per un petit espai en blanc, de manera que formen una columna a l'esquerra del cos del text, en una impaginació força freqüent per al vers narratiu. Hi ha una caplletra de cos més gran al v. 32, que podria indicar una divisió en parts del discurs. El text és escrit en noves rimades, encara que la versificació, pobra i elemental, és força irregular: hi són molt nombrosos els versos tant hipomètrics com hipermètrics, entre 7 i 12 síllabes, sigui pel registre poc acurat d'aquest text o per culpa de la transmissió manuscrita. ${ }^{2}$

Amb repeticions $i$ insistències, amb les quals

1. En l'elaboració d'aquest treball he consultat dubtes paleogràfics a R. Miró, J. de Puig, aclariments lingüístics a $\mathrm{E}$. Prat. A tots aquests amics, moltes gràcies. Tots els errors que hi pugui haver en aquesta edició són, però, de la meva responsabilitat.

2. Per exemple, el v. 9 (e s-truc - ni - ma-les-truch - no.l cal - man-le-var) té 11 síllabes - o un alexandrí coix en el segon hemistiqui, però és massa antic perquè pugui voler ser un alexandrí. expressa conceptes contraris, l'autor ens recorda que totes les empreses humanes, en les quals hauria de prevaler més l'enginy que la força, són vanes i estèrils sense l'ajut i la presència de Jesucrist, exemple i mirall per a l'home, al qual t'has d'encomanar perquè arribin a bon port. Per aconseguir una fita en la vida, en els negocis, hom ha d'actuar d'acord amb uns principis morals ferms. En aquests versos sovintegen uns mateixos conceptes: el poeta recorda que l'home és inferior i limitat per la seva naturalesa humana; per això insisteix que el lector rellegeixi i mediti sovint aquests dictats, on ha de trobar consol i motius per redreçar la conducta:

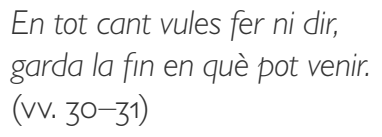

En tot cant vules fer ni dir, garda la fin en què pot venir. (vv. 30-31)

[En tot quan vulguis fer i dir tingues present com pot acabar.]

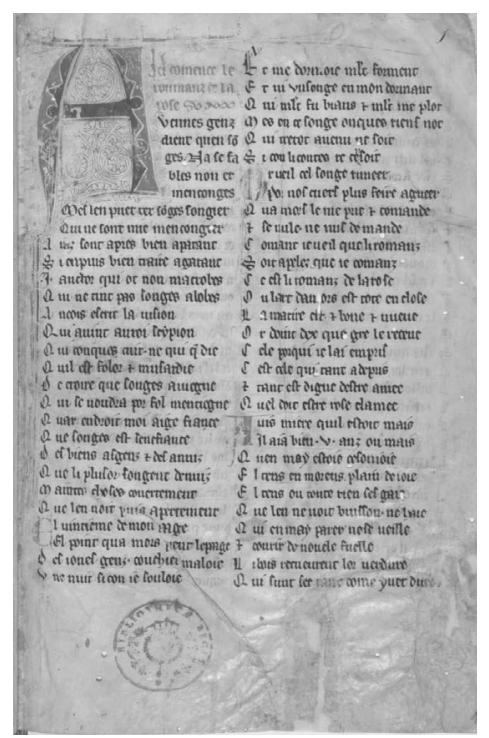

Mostra d'impaginació típica de la narrativa al manuscrit més antic del Roman de la Rose (París, BnF, fr. 1553, finals s. XIII). 
El text és incomplet a causa de la pèrdua del (o els) folis inicial i final, no es conserva cap rúbrica ni colofó que ens informi sobre l'autor ni el títol de l'obra, que no hi ha manera d'identificar i, almenys de moment, roman anònim. No podem saber l'extensió originària del text, tot i que la caplletra del v. 32 ens dóna a entendre que el discurs s'articularia en diverses parts. Tampoc no és fàcil de precisar la finalitat exacta de les màximes que contenen aquests versos, més enllà de la clara intenció moralitzadora. Els trenta-nou versos conservats són, en qualsevol cas, una mostra de poesia moral, tan conreada pels autors medievals, un aplec de dístics amb bons consells, en el mateix estil del Llibre de bons amonestaments (1397), d'Anselm Turmeda, potser el recull més difós i conegut. Es tracta d'una mena de Disticha Catonis casolans inspirats en aquest text escolar llatí, la difusió del qual testimonien diverses versions en català medieval.3 A Catalunya hi ha una rica tradició proverbial i didàctica, al servei de l'adoctrinament moral, provinents també d'obres nostrades, de traduccions de sentències de savis i filòsofs llatins, grecs i del món àrab.

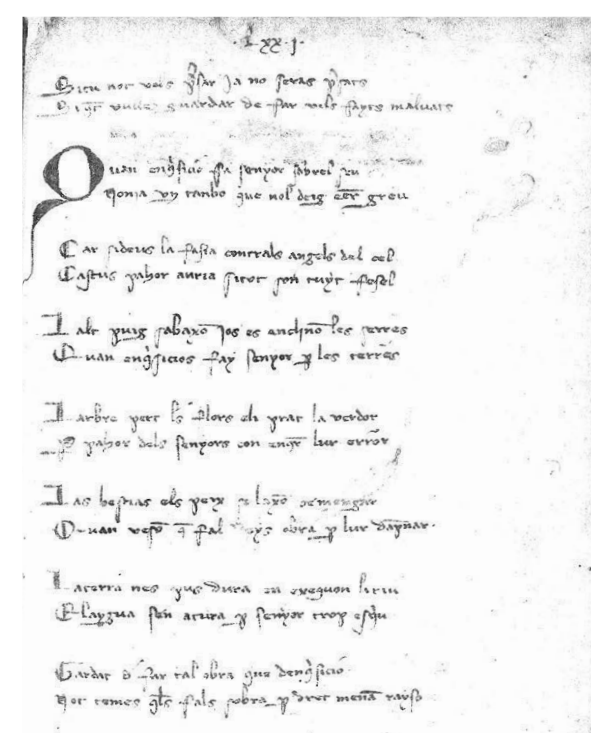

Els Verses proverbials de Guillem de Cervera al Cançoner dels comtes d'Urgell (Madrid, BNE, Reservado 48, f. 71r).

3. Vegeu, per exemple, l'edició d'una de les versions a Closa (1985), i per a més informació sobre el conjunt de traduccions vegeu la base de dades Translat.

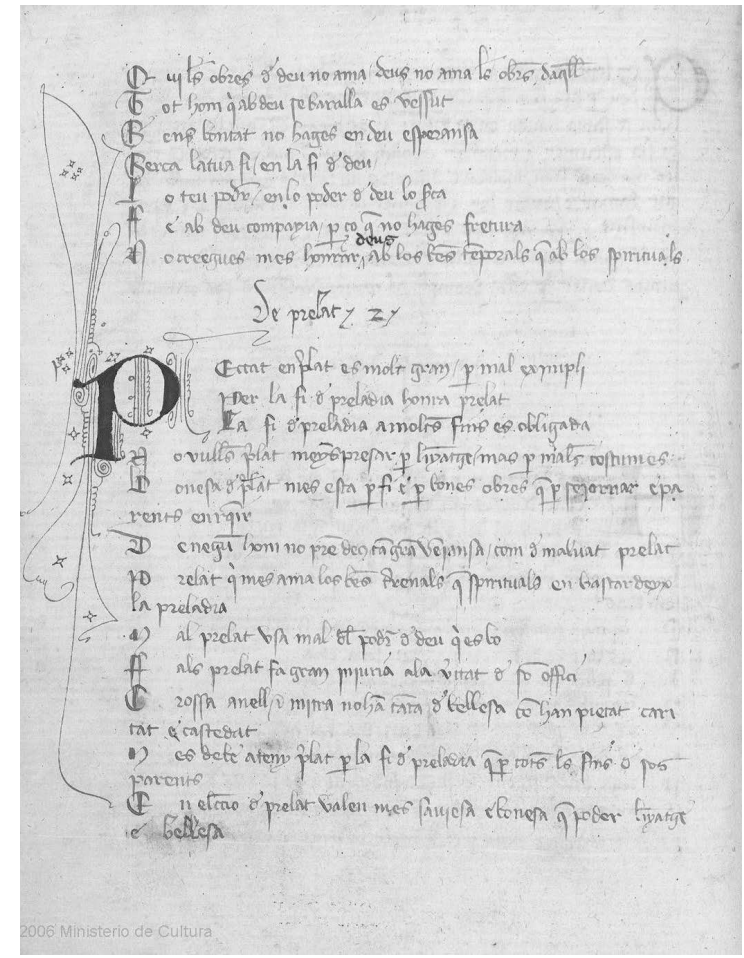

Els Mil proverbis de Ramon Llull (Palma, Biblioteca Pública, ms. 1025 , f. 118v).

Em refereixo, sumàriament, entre d'altres reculls i exemples, als Proverbis (segle XIII), de Guillem de Cervera, altrament conegut com a Cerverí de Girona; a les Paraules de savis e de filòsofs, de Jafudà Bonsenyor (1291-98); o a la Doctrina moral (segle XIV), del gènere gnòmico-didàctic, obra atribuïda a Joan o Lluís de Pacs (antigament atribuïda a Nicolau de Pacs, amb poc fonament). Cal destacar també el Llibre de Doctrina, atribuït a Jaume I o bé (segons el parer de la crítica més recent) a Jaume II, i el Llibre de tres, collecció anònima de sentències del final del segle XIV, imprès a la fi del segle XV. Del Facetus llatí (que es traduiria per 'persona ben educada') se'n conserva també una adaptació catalana: el Facet o Llibre de la Cortesia (final del segle XIV). Altres reculls interessants són els Mil proverbis de Ramon Llull, les Flors o autoritats extretes de les epístoles de Sèneca, ${ }^{4}$ o les Flors de virtut, de les quals Anna Cornagliotti (1975) va editar la traducció catalana. En les obres

4. Lluís Faraudo de Saint-Germain els va publicar tots dos (el 1954 i el 1910, respectivament), en el primer cas segons un manuscrit valencià que atribuiia el text lullià a Salomó. 


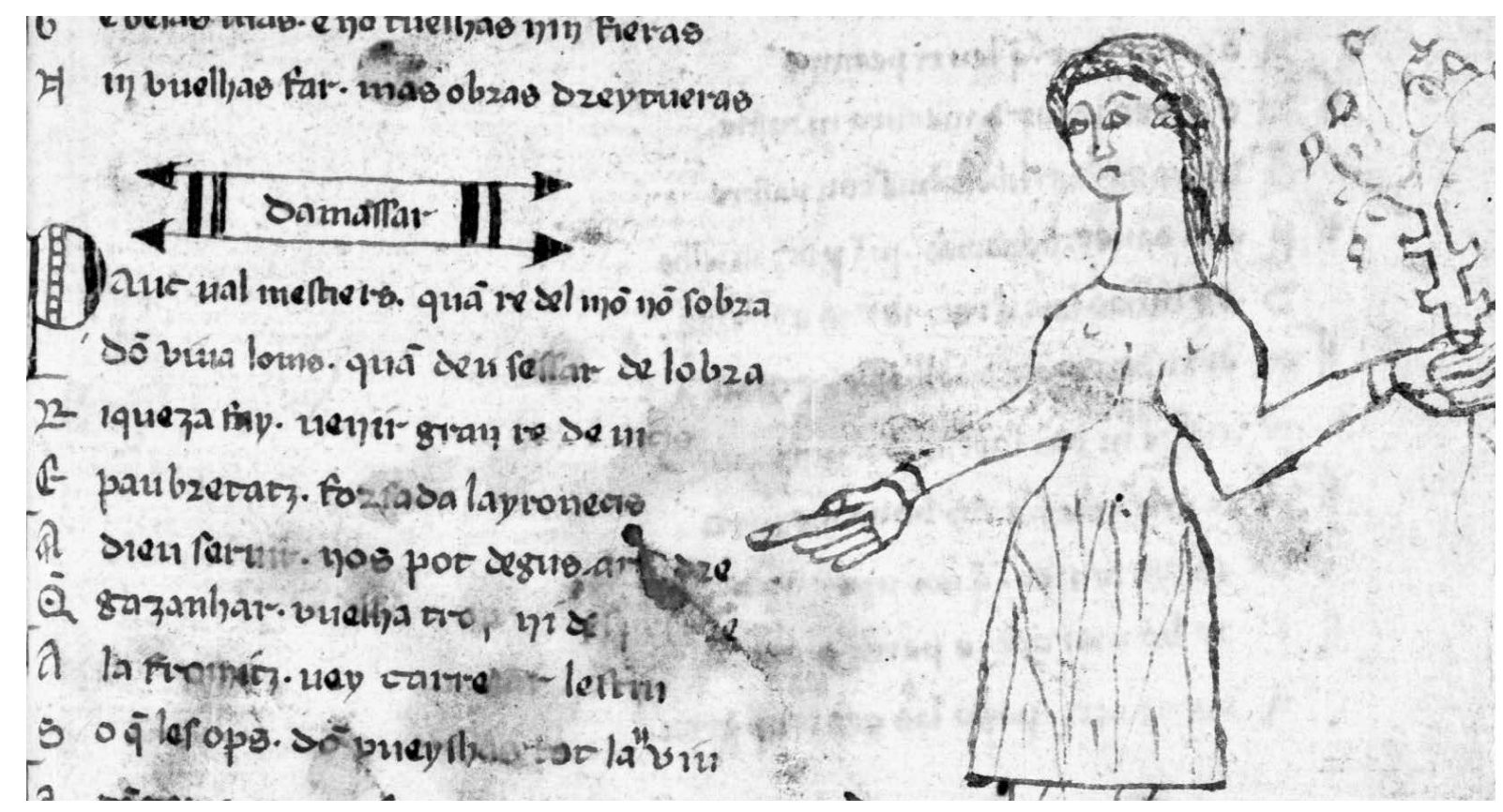

Un altre exemple de literatura sapiencial al segle xIv: el Libret de bons ensenhamens de l'occità Ramon de Cornet, secció «D'amassar», al Registre Cornet (Tolosa de Llenguadoc, Bibliothèque Municipale, ms. 2886, f. 108, datat entre 1340-1360).

de Francesc Eiximenis, Turmeda, Jaume Roig i altres autors medievals hi ha escampats molts proverbis i altres dites vulgars.

\section{Edició del fragment}

Com a primera aproximació a l'estudi del petit recull que presentem, hem pogut identificar alguns proverbis coneguts. Per exemple, al vers 5 hi hem trobat el proverbi codificat «Val més ginys que fortsa» [Ingenium superat vires], conservat en el Liber elegantiarum del notari de València Joan Esteve (Venècia, 1489), però que ja apareix a la crònica de Jaume I. En el Terç del Crestià també llegim: «Açò és ço que dix Salamó, que més val giny que força»]. El vers 31, «garda la fin en què pot venir», ens recorda una altra sentència recollida en el Liber elegantiarum: «de totes coses, hom deu guardar la fì [omnium rerum respiciendus en finis].5 A grans trets, en aquest repertori de màximes morals hi transparenta

5. Tots aquests exemples de proverbis els hem espigolat del llibre de Conca \& Guia (1996), amb una abundosa bibliografia que ens abstenim de repetir. un rerefons de llibres sapiencials, de preceptes evangèlics, de literatura moralitzadora. A voltes aquests versos fan la impressió d'una provatura. Els versos 16-19 apareixen repetits en els següents (Vv. 20-24, que inicien el verso del foli), amb canvis imperceptibles. En definitiva, el text és una altra petita mostra d'una literatura didàctica, d'unes inquietuds religioses, o almenys relatives a l'ordre moral, que tenyeixen la nostra cultura als segles XIV i Xv.

Per editar el text hem seguit els criteris habituals: respectem la grafia original del text, desenvolupem les abreviatures sense indicar-ho, i regularitzem les alternances gràfiques de la i/j i de la u/v, les majúscules i les minúscules, la puntuació i la separació de paraules segons l'ús modern. Per a les elisions vocàliques que no tenen representació gràfica en català actual, hem usat el punt volat. Hem accentuat d'acord amb la normativa ortogràfica actual. Entre claudàtors i punts indiquem la pèrdua física de text o un fragment de vers illegible a causa del mal estat de la còpia. Restituïm entre claudàtors els fragments conjecturats que, tot i mancar el suport físic, ens semblen factibles pel context. 


\section{Text conservat}

(1r)

$[\ldots \ldots \ldots \ldots \ldots \ldots \ldots \ldots \ldots \ldots .$.

com li poràs dar bona fi.

En totes coszes cies ginyós

e ben tractan e coratgós.

No fasses tes coszes a urtsa,

car en mots locs val més giny que fortsa. 5

Emperò no't vules tu refiar

en ton giny, si [no] vols mal far,

car si Déus no·t vol endressar,

e struc ni malestruc no:l qual [matí levar].

Per què en tot cant vules fer

10

reclama Déus per partsoner,

que eyl te vulla endressar,

que en res no't pusques desviar;

e cill reclames per partsoner,

eyl te darà bon adresser.

[...] Sol que tu mouga bon coratge

[e]n tos feyts ni en ton obratge;

perquè és ver, e sol no muda,

que a tot bon cor Déus ajuda.

(1v)

Sol que tu mouga bon coratge en tos feyts ni en ton obratge; perquè és ver, e sol no muda, que a tot bon cor Déus ajuda. Ffiyl, fé ab acort tot cant faràs

e, ci o fas, tart faliràs.

E cant volràs fer nul tractat,

llig e garda aquest dictat,

car ab eyl te poràs acordar

de tots los feyts que volràs far.

En tot cant vules fer ni dir,

garda la fin en què pot venir.

Fiyl, ci tu vols mercadegar

o ci às a vendre o a comprar,

si no saps so que obs às,

llos sabens ne demanaràs.

No't reguesquas axí com fol,

qui [vedat] no॰s del asze lo lop [lo ...ol],

mes cant seràs certificat,

si veus que·t plàssia lo mercat,

20
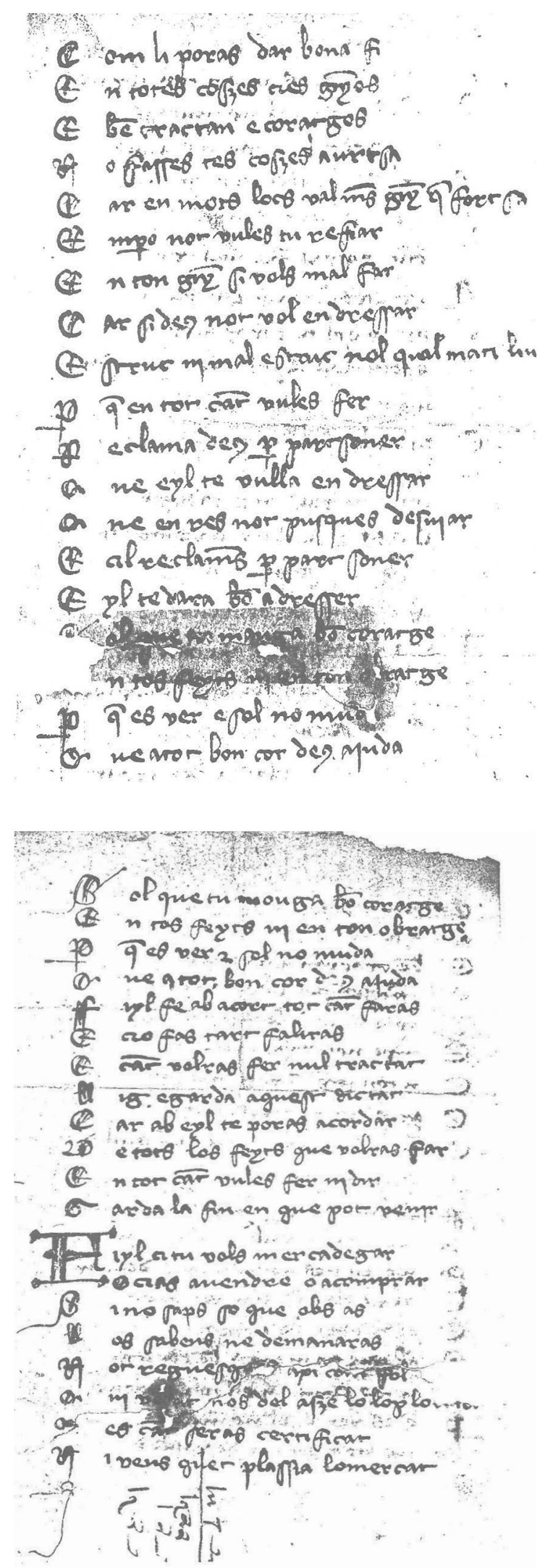


\section{Traducció}

[...] com l'hi podràs dar bona fi. En totes coses sigues enginyós, i tracta els altres amb dretura, i sigues coratjós. No facis les coses de mala manera, ja que en molts llocs val més enginy que força. Emperò no et vulguis refiar del teu enginy, si no vols acabar malament, ja que si Déu no et guia, ni al sortós ni al desgraciat no li cal llevar-se al matí. Per la qual cosa en tot el que vulguis fer reclama a Déu per soci, que ell et vulgui dirigir, que en res no et puguis desviar; i si el reclames per company, ell et donarà bona drecera. Que només et mogui bona intenció en els teus fets i en les teves obres, perquè és veritat i és l'única cosa que mai no deixarà de ser certa, que Déu ajuda a tot bon cor. [quatre versos repetits] Fill, fes amb seny tot allò que faràs i, si ho fas així, difícilment t'equivocaràs; i quan vulguis fer algun tracte, llegeix i tingues en compte aquesta obreta, ja que amb ella et podràs informar de tots els fets que voldràs fer. En tot el que vulguis fer i dir, tingues present com pot acabar.

Fill, si tu vols mercadejar o si has de vendre o comprar, si no saps allò que et convé fer, als savis ho demanaràs. No actuiis així com un foll, que si l'ase no està protegit del llop se l'emporta (?), sinó que quan t'hauràs informat bé, llavors podràs comprar al mercat a un preu debatut [...]

\section{Comentaris}

9. Esmeno matí levar allí on el manuscrit diu «manlevar». Vegeu la nota lèxica corresponent.

16. A l'inici del vers hi ha un mot esborrat.

37. [Vedat], lliçó conjectural perquè el mot no es llegeix bé. - [ [o ??ol], conjectural perquè un forat impedeix la lectura sencera del text, que dóna la impressió que és llarguíssim.

\section{Notes lèxiques}

3. ben tractan(t): 'aquell qui tracta (amb) els altres amb dretura'. - coratge: ' força d'ànim, valor'. Vegeu també el v. 16.
4. .... u urtsa: «anar a l'orsa» o «en orsa» és 'anar de tort, anar de mala manera', com quan es navega amb vent de proa, que provoca la inclinació o la desviació de la nau. El copista, que pertanyia al català oriental, grafia urtsa, però ho fa rimar amb fortsa. Fem constar l'existència d'aquesta grafia anòmala.

8. endressar: 'esmenar, corregir', és a dir 'redreçar, guiar, portar-te per la via dreta'.

9. [a struc, milloraria el text ]. Astruc. És a dir, 'Si Déu no et guia, ni sortós ni desgraciat pots aconseguir res en aquest món malastruc'. - qual: 'cal'. - Proposo editar matí levar allí on l'original diu «manlevar», perquè així el text es fa més entenedor. El sentit sembla que sigui que si Déu no t'ajuda, tant si ets astruc com malastruc, no cal ni que et llevis. D'aquí el criteri per esmenar matí levar.

11. Déus: en català arcaic encara es distingia entre el cas recte Déus (nominatiu i vocatiu) i els casos oblics Déu (la resta), que deriva de l'acusatiu llatí Deum. - partsoner: 'coparticipant' (avui parçoner). És a dir, demana sempre la participació (l'ajut) de Déu en les teves empreses. La paraula en posició de rima es repeteix al v. 14

13. que: 'de manera que'.

15. bon adresser: 'bona drecera'.

18. et sol no muda: 'i és l'única cosa que mai no deixarà de ser certa'.

20. que tu mouga: 'que a tu et mogui'.

22. En català es conserva el refrany: «A qui es muda, Déu l'ajuda», que expressava la suposició que una mudança de casa afavoria la sort.

23. Aquests quatre versos es repeteixen. L'única cosa que sempre és constant (que sol[ament] no muda) és que Déu sempre ajuda qui actua mogut per un bon cor.

24 fe ab acort: 'fes amb seny' (estar en son acord 'estar en l'ús de sa judici', DCVB).

25. ci o fas, tart faliràs: 'si ho fas així, difícilment t'equivocaràs' (si ho fas, tard falliràs).

26. tractat: 'Acció de tractar, de discutir o 
parlar d'un assumpte per arribar a un acord', DCVB.

27. dictat: 'text, obreta', que és el sentit antic que indica el DCVB.

31. garda: 'esguarda, contempla, tingues present'. - - ..venir: cf. «De totes les coses, hom deu guardar la fì. Crec que els versos volen dir que cal tenir sempre en compte l'efecte que produiran les nostres actuacions, el que en resultarà d'haver dit o haver fet.

34. so que obs às: 'allò que et convé fer' (ço de què has ops; haver ops 'necessitar').

35. Ilos sabens: llegiu los sabents 'els savis'.

36. reguesquas: Ilegiu regesques 'regeixis'.

37. Asze és ase? Potser es podria proposar també aquesta altra lectura: «No actuiis com un foll, que no es dol [=no li reca, no li sap greu] a ser [a comportar-se] com lo llop en vedat [de caça]», és a dir, a comportar-se com un insensat, com algú a qui no li importen les regles per què es regeixen els altres. En aquest cas caldria transcriure: «No·t reguesquas axí com fol, | qui vedat no:s dol a sse lo lop». En canvi, si suposem que el mot s'ha d'entendre com a ase, recordem el refrany valencià: «Ase de molts, els \|lops se'l mengen», documentat a Conca \& Guia (1997: 241)

38. cant seràs certificat: 'quan t'hauràs informat bé' (quan podràs actuar no precipitadament i a cegues sinó amb ple coneixement del que fas i de les conseqüències que pot tenir).

39. mercat: 'venda o compra a un preu debatut entre el venedor i el comprador' (DCVB).

\section{Bibliografia citada}

CLOSA, JOSEP, 1985: «Entorn d'una traducció catalana inèdita dels Disticha Catonis», Homenatge al Dr. Antoni Comas, Barcelona, Universitat, 87-93.

ConcA, Maria \& Josep GUIA, 1996: Els primers reculls de proverbis catalans, Barcelona: Publicacions de l'Abadia de Montserrat.

CornagliottI, Anna, 1975: Flors de virtut, Barcelona: Barcino.

$D C V B=A . M$. Alcover \& F. de B. Moll, Diccionari catalàvalencià-balear, Barcelona, Moll, 2001-02. <http://dcvb. iecat.net>

FarAudo de SaINT-Germain, Lluís, 1910: «Flors o autoritats tretes de les Epístoles de Sèneca», Estudis Universitaris Catalans, 4, 193-246 i 391-93.

Faraudo de Saint-Germain, Lluís, 1954: El texto de los «Mil proverbis» de Ramón Llull atribuido a Salomón en un códice valenciano del siglo XIV, Barcelona: CSIC.

Translat: Base de dades de traduccions al català medieval (1300-1500). <http://www.narpan.net/index.php/ translat-db> 


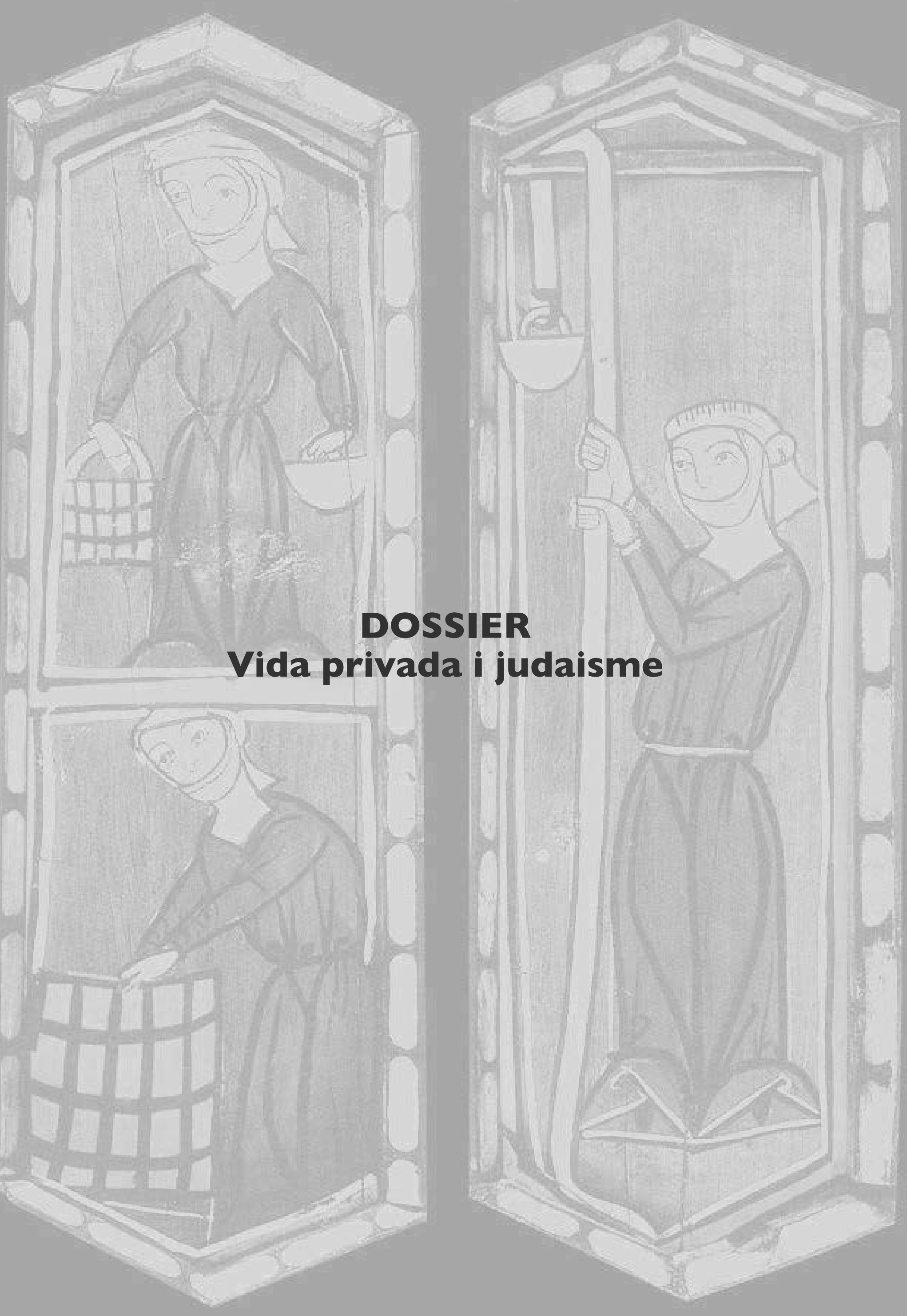


